\title{
Biological Profile of Gout in Obese and Non-Obese Subjects in Yaoundé, Cameroon
}

\author{
Vicky Jocelyne Ama Moor ${ }^{1}$, Daniel Akoa Akoa ${ }^{1}$, Jérôme Boombhi ${ }^{1}$, Ahmadou Musa Jingi' \\ Bertrand Daryl Nzokou Tcheutchoua ${ }^{1}$, Mickael Essouma ${ }^{1}$, Jan René Nkeck ${ }^{1}$, Caroline \\ Ngoufack $^{3}$, Lolitha Noundjeu ${ }^{2}$, Sandrine Sa'a ${ }^{3}$, Yolande Vanessa Ayi Efoua ${ }^{4}$, Madeleine \\ Ngandeu Singwe ${ }^{1}$ \\ ${ }^{\text {I}}$ Faculty of Medicine and Biomedical Sciences - University of Yaoundé I, Cameroon \\ ²Biyem-assi District Hospital, Yaoundé, Cameroon \\ ${ }^{3}$ Yaoundé Central Hospital, Yaoundé, Cameroon \\ ${ }^{4}$ Hôpital de la Caisse Nationale de Prévoyances Sociales de Yaoundé, Yaoundé, Cameroon
}

*Corresponding Author: Bertrand Daryl Nzokou Tcheutchoua, Faculty of Medicine and Biomedical Sciences - University of Yaoundé I, Cameroon

\begin{abstract}
:
Background: Gout, the leading cause of arthritis in adults, is frequently associated with obesity which promotes chronic hyperuricemia. Biological signs seem more severe in obese subjects. The aim of this work was to study the biological characteristics of gout in obese subjects in the city of Yaoundé.

Methods: We carried out a cross-sectional study. The study population consisted of obese and non-obese subjects, suffering from gout, who were compared from socio-demographic and para-clinical characteristics. The Mann Whitney test was used to compare the medians between the two groups. The significance threshold was set at 0.05.

Results: Among the 101 recruited, 44 were obese and 57 were not obese. The median ages of the subjects were 61 [51 - 68] years and 58.50 [53 - 64.75] years respectively for the non-obese and the obese. There was no significant difference between uric acid levels, serum creatinine, total cholesterol, HDL cholesterol, LDL cholesterol, triglycerides between the groups of non-obese and obese. However, we observed that C-reactive protein levels were significantly higher in the non-obese group compared to obese.
\end{abstract}

Keywords: Gout, Obesity, Hyperuricemia, Metabolic Syndrome.

Abbreviation: HDL: High Density Lipoprotein; LDL: Low Density Lipoprotein; BMI: Body Mass Index; CRP: C-Reactive Protein

\section{INTRODUCTION}

Gout is the leading cause of arthrites in adults [1]. It is characterized by an ever increasing frequency and high morbidity [2]. Its global prevalence varies between 1 and $4 \%$, as long as in Cameroon a study carried out in 2007 found a prevalence of 5.9\% [3].

Gout is thus a frequent pathology in our context, responsible for joint pain but also for premature death [2]. This significant morbidity is explained by a strong association between hyperuricemia and cardiovascular and renal diseases, whose relationship increases with the duration of hyperuricemia. Hyperuricemia is responsible for activation of the renin angiotensin aldosterone system, decrease in nitric oxide activity, proliferation of vascular myocytes and insulin resistance. Through these mechanisms, hyperuricemia and gout promotes the occurrence of cardiometabolic pathologies thus worsening the prognosis of these patients [4,5].

Obesity is the most important comorbidity of gout compared to hypertension, diabetes and dyslipidemia[6,7]. In Cameroon, it is present in 78 to $84 \%$ of subjects suffering from gout $[8,9]$. Obesity is associated with gout according to a dose dependent effect as it is responsible for an exponential increase in uricemia in gouty patients, in particular by the secretion of pro-inflammatory cytokines[10,11]. These two mechanisms suggest that the biological profile of gout could vary depending on the body mass index of patients, which explains the higher morbidity of obese gouty patients. The metabolic alterations of gout depend on hyperuricemia and could be amplified by the 
accentuation of the inflammatory process caused by obesity [12]. Therefore, this study aimed to compare the biological profile of gout in obese and non-obese patients.

\section{Material ANd Methods}

\subsection{Study Framework}

We conducted a cross-sectional study from January to April 2019 in 06 hospitals in the city of Yaoundé: Yaoundé Central Hospital, Hôpital de la Caisse Nationale de Prévoyances Sociales de Yaoundé (HCNPS), Biyem-Assi district hospital, Yaoundé University Hospital and the Efoulan district hospital.

\subsection{Participants}

Were included all patients over the age of 18 who met the diagnostic criteria for gout according to ACR / EULAR 2015 or followed for documented chronic gout[13]. Patients with intensive physical activity, on corticosteroid, hormonal contraceptives, or with muscle wasting, ascites and edematous syndrome were not included. All patients with another etiology of arthritis associated with gout were excluded.

The participants were then divided into two groups:

Group 1: Obese patients: $\mathrm{BMI} \geq 30 \mathrm{Kg} / \mathrm{m}^{2}$ or waistline $>102 \mathrm{~cm}$ for men or waistline $>88 \mathrm{~cm}$ for women [14].

Group 2: Non-obese patients: $\mathrm{BMI}<30 \mathrm{Kg} / \mathrm{m}^{2}$ or waistline $\leq 102 \mathrm{~cm}$ for men or waistline $\leq 88 \mathrm{~cm}$ for women.

\subsection{Ethical Considerations}

The study was approved by the institutional research ethics committee of the Faculty of Medicine and Biomedical Sciences of the University of Yaoundé 1. It was conducted in strict accordance with the principles of the Declaration of Helsinki.

\subsection{Data Collection}

Participants were recruited from internal medicine consultation and hospitalization. Data were collected by the principal investigator using a data collection sheet comprising the following information: socio-demographic and anthropometric characteristics and the history of gout.Then a venous sample was taken to carry out dosages of: C-reactive protein, uricemia, creatinemia, total cholesterol, HDL cholesterol, triglycerides, and LDL cholesterol calculated by the Friedwald equation when the concentration of triglycerides was less than $3.4 \mathrm{~g} / 1$.

\subsection{Statistical Analysis}

We built a database using Excel 2013 software, realized analyzes using SPSS software version 22. The data were reported in median and interquartile range for continuous variables and in proportions for categorical variables. The Mann Whitney test was used to compare the medians between the groups. The significance threshold was set at 0.05 .

\section{RESUlTS AND DisCUSSION}

\subsection{Results}

\subsubsection{General Characteristics of the Study Population}

We included 101 subjects, including 57 non-obese with a BMI of 26.80 [24.14 - 27.91] Kg / $\mathrm{m}^{2}$ and 44 obese BMI 32.53 [30.89 - 35.38] Kg / m². The median gout durations were 4.00 [1.00 - 7.75] years for group 1 and 4.00 [2.00 - 7.00] years for group 2. The median ages were similar in the two groups $(\mathrm{p}=0.369)$. The socio-demographic characteristics of the study population are presented in Table 1.

Table1. Characteristics of the study population

\begin{tabular}{|l|l|l|l|}
\hline & Non obese $(\mathbf{n}=\mathbf{5 7})$ & Obese $(\mathbf{n}=\mathbf{4 4})$ & $\mathbf{p}$ \\
\hline Age & $61.00[51.00-68.00]$ & $58,50[53.00-64.75]$ & $>0.05$ \\
\hline Sex ratio (H/F) & 10.4 & 10 & $>0.05$ \\
\hline Sedentary lifestyle, $\mathrm{n}(\%)$ & $22(38.60)$ & $27(61.36)$ & $>0.05$ \\
\hline Hypertension, $\mathrm{n}(\%)$ & $21(36.84)$ & $20(45.45)$ & $>0.05$ \\
\hline Diabetes, $\mathrm{n}(\%)$ & $10(17.54)$ & $8(18.18)$ & $>0.05$ \\
\hline Metabolic syndrome, $\mathrm{n}(\%)$ & $13(22.8)$ & $24(54.5)$ & $<\mathbf{0 . 0 5}$ \\
\hline
\end{tabular}




\subsubsection{Biological Profile}

The non-obese group's uricemia was 87.00 [66.53 - 98.10] mg / 1 compared to 86.13 [74.00 - 100.86] $\mathrm{mg} / 1$. There was no significant difference between the two groups $(\mathrm{p}=0.885)$. The effect of obesity on inflammation in gouty patients was evaluated using C-reactive protein. The CRP of non-obese patients $(24.80$ [12.00 - 96.00] $\mathrm{mg} / \mathrm{l})$ was significantly higher than that of obese patients $(5.50$ [2.50 $30.75] \mathrm{mg} / 1) ; \mathrm{p}=0.002$. Regarding renal function, we did not observe any significant difference between the two groups $(\mathrm{p}=0.213)$. The serum creatinine level of non-obese patients was 12.82 [9.49 - 17.75] mg / 1 compared to 11.09 [9.20 - 14.07] mg / 1 for obese patients.

Table2. Biological profile

\begin{tabular}{|l|l|l|l|}
\hline & Non obese $(\mathbf{n}=\mathbf{5 7})$ & Obese $\mathbf{( n = 4 4 )}$ & $\mathbf{p}$ \\
\hline Uricemia $(\mathrm{mg} / \mathrm{l})$ & $87.00[66.53-98.10]$ & $86.13[74.00-100.86]$ & $>0.05$ \\
\hline CRP $(\mathrm{mg} / \mathrm{l})$ & $24.80[12.00-96.00]$ & $5.50[2.50-30.75]$ & $<\mathbf{0 . 0 1}$ \\
\hline Créatininemia $(\mathrm{mg} / \mathrm{l})$ & $12.82[9.49-17.75]$ & $11.09[9.20-14.07]$ & $>0.05$ \\
\hline Total cholestérol $(\mathrm{mg} / \mathrm{l})$ & $1.56[1.36-2.32]$ & $1.98[1.30-2.45]$ & $>0.05$ \\
\hline HDL cholestérol $(\mathrm{mg} / \mathrm{l})$ & $0.46[0.35-0.55]$ & $0.37[0.34-0.55]$ & $>0.05$ \\
\hline LDL cholestérol $(\mathrm{mg} / \mathrm{l})$ & $1.05[0.76-1.42]$ & $1.45[0.93-1.72]$ & $>0.05$ \\
\hline Triglycérides $(\mathrm{mg} / \mathrm{l})$ & $1.17[0.92-1.50]$ & $1.00[0.93-1.72]$ & $>0.05$ \\
\hline
\end{tabular}

Regarding the lipid profile, total cholesterol was higher in obese patients $(1.98$ [1.30 - 2.45] $\mathrm{mg} / \mathrm{l})$ compared to non-obese patients (1.56 [1.36 - 2.32] mg/l). Likewise, LDL cholesterol levels were higher in the obese group $1.45[0.93-1.72] \mathrm{mg} / \mathrm{l}$ compared to $1.05[0.76-1.42] \mathrm{mg} / \mathrm{l}$. HDL cholesterol was higher in non-obese patients $(0.46$ [0.35 - 0.55] $\mathrm{mg} / \mathrm{l}$ compared to 0.37 [0.34 - 0.55] $\mathrm{mg} / \mathrm{l})$. However, these differences were not statistically significant.

\section{DisCUSSION}

We conducted a cross-sectional study to compare the biological profiles of gout in obese and non-obese patients. It appears that the rates of serum uricemia and serum creatinine are similar in the two groups. In contrast, obese patients had lower CRP and HDL cholesterol, higher total cholesterol and LDL cholesterol levels than non-obese patients.

The main biological marker for gout is uricemia. It serums levels are similar in our study between the obese and the non-obese. These results are in contrast to those found in the literature showing a strong and positive correlation between the body mass index and the uricemia, making the latter one of the main risk factors for obesity $[15,16]$. Our observation suggests that obesity plays a less important role than other factors such as diet and genetics in our population. However, the size of our sample does not allow us to confirm this hypothesis. In addition, CRP, the inflammatory marker evaluated in this study, is higher in non-obese patients; obesity therefore seems to be a factor in controlling inflammation in gouty patients. This observation, similar to that made with uricemia, diverges from numerous studies which report that obesity, which itself causes systemic inflammation, aggravates the inflammation caused by deposits of uric acid crystals $[17,18]$. However, a study from Taiwan on recent changes in clinical manifestations and risk factors associated with gout shows that, despite an increase in body mass index after 1992, the frequency of episodes and the severity of inflammatory signs have significantly decreased[19]. In addition, obesity is associated with hyperuricemia and the latter can constitute a protective factor against the oxidative stress found during gout. In fact, obesity is associated with a predominant production of superoxide dismutase (SOD), an antioxidant enzyme which seems to have a negative correlation with IL- 6 and TNF- $\alpha$, thus reducing the chronic inflammatory process which leads to formation of tophi during gout [20,21]. Obesity could therefore currently have a protective effect on the severity of gout, contrary to what has been observed in the past.

The lipid profile assessment found that obese patients had higher levels of total cholesterol and LDL cholesterol and lower levels of triglycerides and HDL cholesterol. These results, although not significant, agree with those found in the literature and are due to the presence of other cardiovascular risk factors such as physical inactivity and an unbalanced diet in obese patients. We found a predominance of the metabolic syndrome in obese subjects. This predominance of metabolic syndrome in obese subjects was also noted by Moulin et al in Angola in 2016 who had an average of 24.5\% of subjects with metabolic syndrome [22]. In Cameroon, Doualla et al found a higher prevalence, $54.6 \%$ of the metabolic syndrome, which can be explained by the size of their sample, which was larger than ours [9]. The predominance of metabolic syndrome in obese subjects that we obtained can be explained by the fact that obesity is a major 
determinant of metabolic syndrome as described by many studies, including that of Sherling et al in 2017 in the United States. United [22].

\section{CONCLUSION}

Our results suggest that obesity appears to reduce the inflammatory response during gout, and do not have any effect on creatinemia and uricemia.

\section{RESULTS}

[1] Our results suggest that obesity appears to reduce the inflammatory response during gout, and do not have any effect on creatinemia and uricemia.

[2] Ragab G, Elshahaly M, Bardin T. Gout: An old disease in new perspective - A review. J Adv Res. 2017 Sep;8(5):495-511.

[3] Kuo C-F, Grainge MJ, Zhang W, Doherty M. Global epidemiology of gout: prevalence, incidence and risk factors. Nat Rev Rheumatol. 2015 Nov;11(11):649-62.

[4] Strazzullo P, Puig JG. Uric acid and oxidative stress: Relative impact on cardiovascular risk. NutrMetab Cardiovasc Dis. 2007 Jul 1;17(6):409-14.

[5] Baker JF, Krishnan E, Chen L, Schumacher HR. Serum uric acid and cardiovascular disease: Recent developments, and where do they leave us? Am J Med. 2005 Aug 1;118(8):816-26.

[6] Zhu Y, Pandya BJ, Choi HK. Prevalence of gout and hyperuricemia in the US general population: The National Health and Nutrition Examination Survey 2007-2008: Prevalence of Gout and Hyperuricemia in the US. Arthritis Rheum. 2011 Oct;63(10):3136-41.

[7] Ng M, Fleming T, Robinson M, Thomson B, Graetz N, Margono C, et al. Global, regional, and national prevalence of overweight and obesity in children and adults during 1980-2013: a systematic analysis for the Global Burden of Disease Study 2013. Lancet LondEngl. 2014 Aug30;384(9945):766-81.

[8] Madeleine Singwé - Ngandeu, , Christophe Nouédoui, , Eugène Sobngwi, Martial Matiket, Alain Georges Juimo. Mali Medical la goutte en consultation hospitaliere à l'hopital central de Yaounde.

[9] Doualla-Bija M, Lobe Batchama Y, Moutchia-Suh J, Ama Moor VJ, Kamdem F, Lekpa FK, et al. Prevalence and characteristics of metabolic syndrome in gout patients in a hospital setting in sub-Saharan Africa. DiabetesMetabSyndr. 2018 Nov;12(6):1007-11.

[10]Chalès G, Richette P. Obésité, hyperuricémie et goutte. Rev Rhum Monogr. 2016 Feb;83(1):44-9.

[11] Nguyen U-SDT, Zhang Y, Louie-Gao Q, Niu J, Felson DT, LaValley MP, et al. Obesity Paradox in Recurrent Attacks of Gout in Observational Studies: Clarification and Remedy: Recurrent Gout Attacks and Obesity Paradox. Arthritis Care Res. 2017 Apr;69(4):561-6.

[12] Aune D, Norat T, Vatten LJ. Body mass index and the risk of gout: a systematic review and dose-response meta-analysis of prospective studies. Eur J Nutr. 2014 Dec;53(8):1591-601.

[13] Neogi T, Jansen TLTA, Dalbeth N, Fransen J, Schumacher HR, Berendsen D, et al. 2015 Gout classification criteria: an American College of Rheumatology/European League Against Rheumatism collaborative initiative. Ann Rheum Dis. 2015 Oct;74(10):1789-98.

[14]Ndiaye MF. Obésité en Afrique: définitions et épidémiologie. J AfrD’Hépato-Gastroentérologie. 2007 Apr;1(1):71-5.

[15] Nakamura T. [Historical review of gout and hyperuricemia investigations]. Nihon RinshoJpn J Clin Med. 2008 Apr;66(4):624-35.

[16] NdongAtome GR, NgouaMeyeMisso R-L, Sima Obiang C, Onanga R, NkogueMba D. Hyper-Uricemia and Gouty Access in the Adult Population of the Southeast of Gabon: Biochemical Aspects. Dis Basel Switz. 2018 Mar 8;6(1).

[17] Thottam GE, Krasnokutsky S, Pillinger MH. Gout and Metabolic Syndrome: a Tangled Web. CurrRheumatol Rep. 2017 Aug 26;19(10):60.

[18] Inflammation in gout: mechanisms and therapeutic targets. - PubMed - NCBI [Internet]. [cited 2019 Oct 25]. Available from: https://www.ncbi.nlm.nih.gov/pubmed/28959043

[19] Preitner F, Laverriere-Loss A, Metref S, Da Costa A, Moret C, Rotman S, et al. Urate-induced acute renal failure and chronic inflammation in liver-specific Glut9 knockout mice. Am J Physiol Renal Physiol. 2013 Sep 1;305(5):F786-795.

[20]Chen S-Y, Chen C-L, Shen M-L, Kamatani N. Trends in the manifestations of gout in Taiwan. RheumatolOxf Engl. 2003 Dec;42(12):1529-33.

[21]Zhou Y, Zhao M, Pu Z, Xu G, Li X. Relationship between oxidative stress and inflammation in hyperuricemia: Analysis based on asymptomatic young patients with primary hyperuricemia. Medicine (Baltimore). 2018 Dec;97(49):e13108. 
[22] Nkeck JR, Singwé-Ngandeu M, Moor VA, Chedjou J-P, Doualla M-S, Mbacham WF. Evaluation of Oxidative Status of Patients with Gout Attack in a Cameroonian Urban Hospital. Open J Rheumatol Autoimmune Dis. 2017;07(02):111.

[23] Moulin SR, Baldo MP, Souza JB, Luchi WM, Capingana DP, Magalhães P, et al. Distribution of Serum Uric Acid in Black Africans and Its Association With Cardiovascular Risk Factors. J Clin Hypertens. 2017 Jan;19(1):45-50.

[24]Doualla M, Kamdem F, Lekpa FK. AB0874 Characteristics of gout in cameroon, central africa: a hospitalbased study. Abstracts Accepted for Publication [Internet]. BMJ Publishing Group Ltd and European League Against Rheumatism; 2017 [cited 2018 Nov 18]. p. 1362.2-1362. Available from: http://ard.bmj.com/lookup/doi/10.1136/annrheumdis-2017-eular.6990

[25] Sherling DH, Perumareddi P, Hennekens CH. Metabolic Syndrome: Clinical and Policy Implications of the New Silent Killer. J Cardiovasc PharmacolTher. 2017 Jul;22(4):365-7.

Citation: Vicky Jocelyne Ama Moor, et.al., (2020). "Biological Profile of Gout in Obese and Non-Obese Subjects in Yaoundé, Cameroon”, International Journal of Clinical Chemistry and Laboratory Medicine (IJCCLM), 6(1), pp.25-29. DOI: http://dx.doi.org/10.20431/2455-7153.0601005

Copyright: (c) 2020 Authors, This is an open-access article distributed under the terms of the Creative Commons Attribution License, which permits unrestricted use, distribution, and reproduction in any medium, provided the original author and source are credited. 